\title{
Die Überwindung der Inkohärenz des Internationalen Privatrechts der Bank- und Versicherungsverträge
}

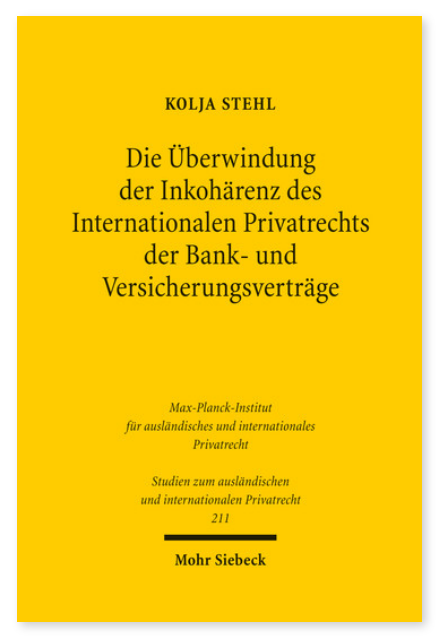

2008. XVIII, 398 Seiten. StudIPR 211

ISBN 978-3-16-151396-1

DOI 10.1628/978-3-16-151396-1

eBook PDF $89,00 €$

ISBN 978-3-16-149684-4

fadengeheftete Broschur 89,00€
Das Internationale Privatrecht der Bank- und Versicherungsverträge ist gegenwärtig in verschiedenen Rechtstexten enthalten. Das Übereinkommen von Rom über das auf vertragliche Schuldverhältnisse anzuwendende Recht von 1980 erfasst neben den Bankverträgen nur einen Teil der Versicherungsverträge. Die verbleibende Lücke wird zum einem durch das Internationale Privatrecht der Versicherungsrichtlinien und zum anderen durch Kollisionsnormen rein nationalen Ursprungs geschlossen. Da die Rechtstexte bei der Bestimmung der anwendbaren Rechtsordnung verschiedene Konzepte verfolgen, zeichnet sich das geltende Internationale Privatrecht der Bank- und Versicherungsverträge durch einen Mangel an Kohärenz aus.

Kolja Stehl stellt sich die Aufgabe, diese Inkohärenz zu überwinden. Den Ausgangspunkt bildet dabei die These, dass de lege ferenda Bank- und Versicherungsverträge im Internationalen Privatrecht einer gemeinsamen Regelung unterworfen werden sollten. Diese These wird von der Vorstellung getragen, dass auf die kollisionsrechtliche Behandlung der Vertragsbeziehungen, die Banken und Versicherer zu ihren Kunden unterhalten, vergleichbare Gestaltungsfaktoren einwirken. In beiden Fällen gilt es, das Ziel, grenzüberschreitende Finanzdienstleistungen zu ermöglichen, mit dem Schutzbedürfnis bestimmter Kunden in Einklang zu bringen. Der Autor schlägt vor, im Zuge der Umwandlung des Übereinkommens von Rom in ein Gemeinschaftsinstrument und anläßlich seiner Aktualisierung das Internationale Privatrecht der Bank- und Versicherungsverträge neu zu gestalten und zusammenzuführen.

Kolja Stehl Geboren 1976; Studium der Rechtswissenschaft in Deutschland, Frankreich (Maîtrise en Droit, Aix-en-Provence) und England (Magister Juris, Oxford); 2002-2005 wissenschaftlicher Mitarbeiter an der Universität Bonn; 2008 Promotion; derzeit Rechtsanwalt bei Hengeler Mueller.

Jetzt bestellen:

https://mohrsiebeck.com/buch/die-ueberwindung-der-inkohaerenz-des-internationalen-privatrechts-der-bank-undversicherungsvertraege-9783161513961?no_cache=1

order@mohrsiebeck.com

Telefon: +49 (0)7071-923-17

Telefax: $+49(0) 7071-51104$ 